\title{
1037 Blended Learning Strategies for Advertising Design Studies
}

\author{
Gladys Lam Wai Ling
}

44-53

Technological developments have brought profound challenges to design education. To understand how design educators adapt to new technological directions, this article examines student feedback from advertising design courses that apply blended learning approaches. This study identified three blended learning strategies conducive to meaningful learning: timely and meaningful feedback; engagement with real world tasks; and support from expert tutors. This article also discusses potential resistance and challenges in implementing instruction in blended technological environments.

\footnotetext{
\#blended learning approach \#design studio pedagogy \#student learning experience \#student perception \#meaningful feedback
} 


\section{Introduction}

The astronomical development of technology has brought profound challenges to design education. With the market of personal handheld devices becoming more mature and unlimited authentic resources becoming available online, learning can occur anywhere, anytime. Thus, there has been a rapid increase in accredited online courses offered by universities around the world. Technology communication allows students to control the time, place, and pace of their learning. Students are increasingly demanding a quality learning experience with convenience and flexibility. The role of the teacher is to foster a learning environment that is learner-centered and focused on the process of delivering a quality learning experience (Beetham and Sharpe 2013, 31-48).

The learning experience is one of the core components of student satisfaction and academic success. Thomas Fischer (2004) argued that design studio disciplines need to move to the next stage of their existence in terms of what they can deliver. New models are now emerging in response to changing needs. There may be a virtual studio where design students learn by doing things remotely. Technologies have changed not only how students learn, but also ways that students expect to learn and behave. How should design educators adapt to the needs and challenges of this new technological era?

\section{Background}

Design education has a long tradition of using studio pedagogy, in which teachers provide feedback and suggestions to students on their designs throughout the creative process. This is done face-to-face. Such communication generates energy and enthusiasm that helps students remain motivated throughout the design pro- cess. The teachers are the domain experts who guide and advise students on their projects. Student-instructor interaction is central to studio-based educational practices. In this setting, on-the-spot communication between students and teachers is spontaneous and contagious, but also viewed as "off the lip" (Meyer 2003, 61). Students must remember what has been said and be mentally and verbally quick to respond and clarify their responses.

Blended learning is the integration of synchronous (face-to-face) and asynchronous (text-based Internet) learning experiences (Garrison and Kanuka 2004, 96). What distinguishes blended learning from traditional classroom-based and online courses is the combination of in-class teaching and out-class learning through computer-based technologies. It is characterised by the use of multiple instruction and delivery channels that can retain the best of face-to-face and online learning experiences. Asynchronous Internet communication has the ability to facilitate an important reflective element because it emphasises written communication. Writing encourages reflection and thinking both creatively and critically. Although some competency is required to write skillfully, all students are provided with an opportunity to learn how to clearly express themselves in written form.

Communication can also provide a permanent record and thus expand learning time. Students can revisit instructors' comments as needed. The communication is accurate and no information is lost. Written comments are often less intuitive and better thought through because instructors can think, research, and provide feedback. The most well-known model of blended learning is Anthony Picciano's Blending with Purpose Multimodal Framework (Picciano et al. 2013, 2). Picciano's framework comprises six objectives for educators to take into account for planning their teaching design and delivery, which include con- 
tent, social/emotional, dialectic/questioning, collaboration, synthesis/evaluation, and reflection. The essence of this model is the ability to meet the needs of a wide range of students with different backgrounds, learning styles and personality types. There is evidence that blended learning has the potential to be more effective and efficient at constructing meaningful learning experiences than traditional learning methods (Kintu et al. 2017, 11). Therefore, blended learning has become an essential approach to the future of education. However, success depends on a well-designed strategy to effectively integrate Internet technology with the most desirable and valued aspects of face-to-face learning.

An effective blended learning setting requires the design of learning tasks, learning support, and learning resources (Herrington et al. 2005). Learning support refers to the capacity to interact with systems, peers, and tutors in the learning process. Students often turn to their peers for company and seek support and advice from their tutors to guide their projects. Providing this support in a blended learning setting establishes a sense of community and promotes higher-order thinking and conceptual development that is often not achievable in an individual learning setting (Brook and Oliver 2004).

What is needed in a blended learning setting is not only the use of technology but a blended learning strategy. Such a strategy is a deliberate set of learning activities and an environment that engages learners in a process that results in the required learning outcomes. Jane Herrington and Tom Reeves identified ten design principles that characterise authentic learning tasks: realworld relevance; ill-defined tasks; complex tasks; opportunities to examine, collaborate and reflect; going beyond domain specifics; integration with assessment; creating valuable products; and allowing for competing solutions. These ten design principles also apply to effective learn- ing environments in which technology is present. In addition, David Boud and Michael Prosser (2002) argued that high quality learning activities must demonstrate four principles: engagement of learners; acknowledgement of context; challenge for learners; and the involvement of practice. Blended learning offers opportunities to deliver on several of these principles.

Design studio pedagogy has a long tradition of offering project-based learning and mentoring support to students. With the introduction of technology-facilitated classroom management platforms that allow chat rooms, forum discussions, and blogging for community learning, learning support has never been lacking. However, research on applying blended learning strategies to project-based studies has found that faculty members and students do not benefit from using eLearning systems (Ma 2016). In a study of engaging creative media students' motivation, the author suggested that faculty should give students more power over their learning process with their projects because autonomy is a primary motivator (Oh et al. 2018). Learners live in a digital world where they can retrieve information easily and communicate with almost anyone. Flexibility and convenience are increasingly important in the technological age, and it is inevitable that educators will adapt to this new direction. Thus, more research is required to gain a deeper understanding of students' perceptions on effective blended learning approaches to design education.

\section{Research Questions}

This study examines blended learning strategies for project-based advertising design courses. It aims to find out the determining factors in student satisfaction and understand the essence of the relationship between students' learning experience and the blended technological world. 
The research questions that guide the study are as follows:

1. How do undergraduates perceive and experience their advertising design courses?

2. What blended learning approaches do students find effective?

\section{Research Context and Methodology}

The sample was collected from advertising design courses at the School of Communication, Hong Kong Baptist University. Formal written feedback was solicited from students at the end of their courses over eight academic years. These courses were offered by the Communication Studies Department to undergraduate students enrolled in the bachelor's of social science (Hons) program in communications, majoring in either public relations and advertising or digital graphic communication. The design courses under investigation included Advertising Design and visualisation, Advanced Advertising Design and Visualisation, Advertising Copywriting and Guerrilla Advertising. The courses ran for 13-14 weeks, three hours a week, with an average enrollment of 24 students. These students were Year 2 and Year 3 communication students majoring in either advertising (PRA) or digital graphic communication (DGC). The average ratio of female to male in the classes was approximately 7:3. Participation was voluntary with the response rate ranging from 28 percent to 88 percent.

The feedback was collected during the last week of the lessons and released to the course instructor within two months. The feedback was collected via online questionnaires, with eight questions to assess aspects such as course preparation, delivery, and learning environment on a five-point Likert-scale. The questionnaire also included three descriptive questions to invite respondents to describe their experience in their own words: 1)
Describe some good points about the course; 2) Describe some areas of the course that could be improved; 3) other comments. The quantitative data indicated students' levels of satisfaction regarding the overall teaching effectiveness of the courses, but the data did not provide much information on the core factors behind this satisfaction rating. Therefore, the main data was derived from the students' individual written narratives. Unlike reflective journal assignments, formative feedback by participants at the end of a course is a way to evaluate the effectiveness of the teaching and improve the course in all dimensions, such as preparation, pedagogy, delivery, and learning environment. All of the responses were anonymous. Because of the nature and timing of the survey, the students had no reason to please the instructor to obtain a good grade. Thus, the narratives were true to the respondents' experience and based on their personal judgment.

The method used was qualitative inquiry with the phenomenological approach. The study of phenomenology pertains to the analytical and descriptive experience of individuals, emphasising their first-hand descriptions of phenomena (Creswell 2013). During the analysis, excerpts and quotes were grouped based on the latent meanings expressed by each participant. Through clustering the invariant constituents, or themes, found in the narrative descriptions are uncovered during the reduction process. Only themes that are representative by each class of participants are checked against the overarching topic, which in this case is blended technology. By outlining the reoccurring and prominent themes across all participants, common themes were identified such that only dominant phenomena with high consistency were considered. Finally, the most essential elements that informed the experiences were conceptualised. In this case, the individual textural-structural descriptions of each participant were not applicable. A composite description of the "meanings and essences of the experience, representing the group as a whole" was presented 
instead (Moustakas 1994, 121). The narratives have remained in their original language and a selected few have been presented in the findings.

\section{Results and Discussion}

Three themes were identified from the analysis of the data: meaningful and timely feedback, real world activities and supportive expert teachers.

Meaningful in this context refers to giving feedback that students appreciate, feedback that provides value to them, and helps them fulfill their purpose for the course. In examining the technology that facilitated the learning environment, students appreciated "meaningful comments" and "prompt replies." One student cited an incident in which she "was desperate" and wrote an email to her teacher late at night. She was pleased to receive a quick reply. With technology, students can approach their instructors with their own design problems anytime and anywhere through technology-mediated communication. Teachers can provide help when students are most in need. Giving students what they need when they need it does not mean that they are being encouraged to ask frivolous questions. It is meant to show consideration of their needs when they call for support. Technology facilitated communication enables teachers to differentiate the individual needs of students. It facilitates personalised learning and student-centered education. It also avoids an overabundance of opinions because it is the learner who invites the feedback. Some students do not like tutors to intrude on their creative endeavors. Teachers must learn when to give comments and when to stop giving them. Technology-mediated communication helps teachers identify such needs.

Students of PRA and DGC from the Advertising Design and Visualization course wrote the following comments:
"I learnt a lot from Gladys' class, no matter advertising knowledge from her real field experience or from her fruitful teaching. I think Gladys is really a good, responsible teacher and she treats us very well. For example, one time I was desperate in creating new ideas for our print ad, I wrote to her through student mail [and] unexpectedly got the answer from her very soon as it is almost very late at night. However, Gladys being a strong passionate and dedicated teacher, she gives me a prompt reply plus offering very meaningful comments on my print ad. I am so glad to have such a great teacher and I hope to continue learning from her :))"

"Nice and responsible tutor. Always have a quick email reply, very appreciate $=$ ]"

The students also enjoyed seeking the teacher's "professional advice" outside class and viewed this as "valuable guidance." The students said that the teacher "judges right and criticises right" and her comments were "constructive," "clear," "useful," and "inspiring."

"This class gives us many chances in practicing execution, it is a great chance for us to make an improvement in doing advertising. The lecturer gives a big freedom for us to develop our creativity and also gives us many opinions in our works. That's great!!!”

"She is creative. And she really knows how to art direct. She judges right and criticises right."

Clear and precise feedback is paramount in design education, whether it is in a traditional face-to face or technologically mediated settings. Written feedback requires special attention and skills. To achieve clear feedback, it is better to write in short paragraphs or in point form. Different stages of the creative process require different formative feedback. During the idea-generating phase, students ask for advice on the potential of their ideas from a pool of rough concepts. 
Under normal circumstances, feedback includes:

1. Choosing the best potential idea and backing it up with reasons.

2. If nothing appears to be appropriate, provide direction.

3. Offer suggestions, if it appears to be helpful.

4. Encourage idea development.

During the idea execution phase, students ask for advice on design layouts and production. Comments could be made on refining the art direction and copywriting. The core task is to make sure that the idea can be effectively conveyed through appropriate executions. For clarity and elaboration, both parties could attach layouts, examples and reference links to their communications.

Technologies have caused a revolution in creative production through the Internet and this has materialised in real world activities. Anyone can post his or her creative work on YouTube, social media and many other online platforms. The Internet has become a dynamic medium for interconnecting people and co-creating. These changes in social systems have transformed the ways designs develop, based on knowledge, collaborative processes, and cross-disciplinary practices (Sanders and Stappers 2008, 8-9). Design educators can use social media to design all sorts of simulated tasks based on real world activities. Meetings with "real" people or launching "live" projects enables students to better understand the societal context and their own potential as prospective professionals.

In this study, the students considered their learning effective by launching their projects on the Internet and joining competitions. They said that "having a real campaign" was "really great." It helped them "learn by experiencing the real situation" and created opportunities for them "to think deeply about the practical problems." They also found the project to be "really challenging" and said that "watching our own project be shown to society was exciting." Launching a "real" campaign helped students learn "more practical knowledge" and "made the course more interesting." They remarked that it was "meaningful" and "valuable" to have an opportunity to join a real world competition that was "so interesting," and said it "really inspired us to learn."

Students of PRA and DGC from the course of Guerilla Advertising gave the following comments:

"Watching our own project be shown to society is an exciting time for me. The final project is really a challenge to me."

"It's nice to have our work launched, and receiving feedback from the public. Got more practical knowledge of launching a campaign."

"Lots of examples to help us understand this up-todate hot topic. It is really great to have a chance to visit the advertising firm and get the really updated example to understand this trend of advertising thoroughly. The practical part of having a real campaign can make everyone learn through experiencing the real situation."

The students also showed interest in participating in relevant creative industries events such as "guest talk" and "agency visit." They said that they like listening to "real design field experience" because they were keen on preparing their "portfolio" for their "future design career."

"Miss Gladys' lesson is always eventful, innovative and interesting. Her homework and project made me learn a lot and it was rewarding. The most lovely part of Miss Gladys' lessons were that she always shared a lot of her real design experiences in the field, which prepared me massively to prepare my future design career path." 
Participating in a real competition was very challenging and practical at the same time to the students as they could put their experience into their portfolio.

In the traditional classroom, the teacher often collaborates with industries and invites practitioners to brief the students or provide face-toface critiques. In the technological age, these activities can be done in a virtual environment. Creative reviews are critical in design education because they simulate professional practice. Instructors need to systematically evaluate the effectiveness of advertising campaigns to promote students' critical thinking. Students need to nurture critical thinking skills to inform the right decisions when choosing the best potential idea. Although the mentor is usually a professional expert, creative work is subjective in nature. By inviting client briefings or professional judgments, students can learn from a diversity of people and benefit from different opinions of those from different backgrounds. Involving industry professionals to provide a few important creative reviews before the final critique would be ideal. Virtual judging can also save commuting time for busy practitioners.

The final theme being supportive expert tutors refer to those who have extensive knowledge, experience and ability in a particular design profession. When the students were asked to describe some good points about their course, they repeatedly mentioned their teacher. The students perceived the teacher as "very warmhearted" and "passionate," "dedicated" and "always ready to help." She "used her extra time" "to give support" to the students. The students said the teacher was "really kind" and "treated us very well." They admired her because she was "a veteran" with "lots of industry experience" that "gives us a lot of inspiration." The students expressed their admiration and hopes to continue to be taught by her.

\begin{abstract}
"As Gladys is a professional creative advertiser, I would love to seek her continued experience sharing in her real-advertising field. Listening to her experience is really fruitful to $m e$ :))"
\end{abstract}

"I think it is so great that the lecturer is an expert in this field. I really admire her and I hope to continue to attend the classes that she teaches."

"She is really kind and always ready to help with her great competency of advertising. I love her!"

Design educators are usually domain experts. Expertise in the field helps cultivate critical and creative thinking skills in the students. However, not all experts are good teachers. Merely being an expert is not enough. The students looked for a dedicated, passionate, and supportive expert. Joe Ruhl (Ruhl 2015) argued that teachers should possess two loves; love for the subject and love for the kids. It is "genuine, decisional and puts the other person first" (ibid., 47) kind of love that motivates and inspires students in a powerful way.

What is keeping educators from integrating blended learning? Formative feedback is labour intensive, both for the learners and the tutors. Online feedback for teachers is more labour intensive than face-to-face communication due to the amount of time required to respond to questions. To provide feedback, teachers must regularly read and comment on the students' postings. Educators have often said that written communication may not be as effective as speaking face-to-face. However, written communication could become clearer if the core subjects were presented in points supported by references. Even without that, written communication allows students to fill in knowledge gaps through their own inquiries and gives them access to unlimited online information.

Interactions with students after class take up teachers' personal time. It is the teacher's decision whether to embrace the students' participation 
outside the classroom or to end the interaction after class. Students learn this on the first teaching day when the teachers establish the classroom rules. Imagine if teachers spoke about the rules on the first day of the class and either required the students to send emails at least one day prior to an appointment or welcomed students to drop by their office for advice. Given that the core learning in design education is to complete a project, for a teacher, making himself or herself accessible is important. Students can find someone to turn to for support and guidance and respond to their questions during the creative process. However, this is not always possible for teachers and professor-track educators who have a heavy workload and a demanding publishing schedule.

Technological glitches have also hindered the willingness of teachers to adopt the blended approach. Although there have been classroom management platforms such as Moodle and Blackboard, students and teachers might not feel comfortable using them as channels for communication. These e-platforms require online logins and take time to load. Even then, notifications are not always available. Blogs for students' reflections, for instance, required a long time to load and could not be downloaded as a file. It was not user friendly and some interfaces could only be displayed properly on a computer, not a handheld device. People are creatures of behaviour and once they become used to a certain platform, they stick to it. For example, most of the students preferred to communicate via email, Facebook Messenger or WhatsApp. These communication technologies are very convenient and reliable in terms of their pop- up notifications. Educators should allow for flexibility and not limit communications to a specific platform. If the platform is too rigid or abrupt, a change may produce resistance and restrict interactivity. Thus, as long as teaching and learning activities take place, we should not limit them to classroom management platforms, although this would mean that universities would not have a history of documented conversations.

To address the concerns above, universities could support teachers by providing release time and recognizing that technological interactions are time-consuming. They could also provide instructor training when technological tools are introduced. In a teaching culture in which adaptability has become the golden currency, it is important to support teachers who are guiding learning in a new environment and are learners themselves. If resources are provided in a personalised way to both teachers and learners, blended learning can evolve dynamically, in a managed way, toward a more interactive and successful pedagogy. What matters is not only how technology can be integrated, but how learning can occur in an enhanced and engaged way.

\section{Conclusion}

A qualitative enquiry into advertising design courses revealed three effective blended learning strategies: meaningful timely feedback, real world tasks, and supportive expert tutors. Design education fosters learning by devising projects and helping students learn through feedback provided throughout the creative process. The most important skills teachers should have include knowing how to facilitate learning, design meaningful activities, and create an appropriate environment beneficial to students' learning experience. When using technology, the quality of the experience is more important than the use of the technology itself. Technologies overcome barriers of distance and time to bring everyone together, helping students learn. We need instructors who have instruction skills in both traditional classrooms and virtual environments so that they can handle students' changing expectations, behaviours, and needs. Many educators still insist on face-toface communication in their teaching and learning activities. They should learn the positive impact of 
relinquishing control to the learner. An instructor's decision to implement a blended learning environment and use technology in his or her course depends on the faculty's preparedness to effectively facilitate and manage both online and faceto-face discussion and interaction. Beyond that, it requires teachers to be flexible, committed, and have a positive mindset (Markoff 2014). It also calls for school support and leadership to facilitate change and overcome resistance.

\section{Limitations and Potential Further Investigations}

The study was limited to an examination of students' perception of their experience in advertising design courses, primarily with a focus on the development of technology. While individual perception is useful to understand factors behind the phenomena examined, self-reported data includes a degree of subjectivity. To further understand design teaching with technology, future research may consider studying a broader context for the learning experience in design education, for instance: mistakes and learning processes (Wenzel 2002), design making and thinking (Mitcham 2001), critique and learning experience (Hokanson 2012). 


\section{Bibliography}

Beetham, Helen, and Rhona Sharpe. Rethinking Pedagogy for a Digital Age: Designing for 21st Century Learning. London: Routledge, 2013.

Boud, David, and Michael Prosser. "Key Principles for High Quality Student Learning in Higher Education: A framework for Evaluation." Educational Media International 39, no. 3 (2002): 237-245.

Brook, Christopher, and Ron Oliver. 2004. “Online Learning Communities: Exploring the Impact of Group Size on Community Development." Paper presented at Ed-Media 2004, World Conference on Educational Multimedia, Hypermedia \& Telecommunications, Lugano, Switzerland, June 21-26, 2004.

Creswell, John W. Qualitative Inquiry and Research Design: Choosing among 5 Traditions. San Francisco, CA: Sage Publications, 2013.

Fischer, Thomas. "The Past and Future of Studio Culture." Appeared in the October 152004 issue of ArchVoices.

Garrison, Randy D., and Heather Kanuka. “Blended Learning: Uncovering its Transformative Potential in Higher Education." Internet and Higher Education 7, no. 2 (2004): 95-105.

Herrington, Jane, Tom C. Reeves, and Ron Oliver. "Creating Authentic Learning Environments through Blended Learning Approaches." In Handbook of Blended Learning: Global Perspectives, Local Designs, ed. Curtis Bonk and Charles Graham. (New York: Jossey Bass, 2005), 502-517.

Hokanson, Brad. "The design critique as a model for distributed learning." In The Next Generation of Distance Education, Boston: Springer, 2012.

Kintu, Justice M., Chang Zhu and Edmond Kagambe. "Blended Learning Effectiveness: The Relationship between Student Characteristics, Design Features and Outcomes." International Journal of Educational Technology in Higher Education 14, no.7 (2017). DOI 10.1186/s41239-017-0043-4

Ma, Henry. "Study of Blended Learning Approach for Project-Based Learning." Paper presented at the Asia-Pacific Social Sciences Conference, Kyoto, Japan, November 22-24, 2015.

Markoff, Monique. "Blended Learning and the Future of Education." Youtube TEDx Talks. Published on May 6, 2014. https:// www.youtube.com/watch?v=Mb2d8E1dZjY.

Meyer, Katrina A. “Face-to-face versus Threaded Discussions: The Role of Time and Higher-order Thinking." Asynchronous Learning Networks 7, no. 3 (2003): 55-65.
Mitcham, Carl. "Dasein versus design: The problematics of turning making into thinking." International Journal of Technology and Design Education 11, no.1 (2001): 27-36.

Moustakas, Clark. Phenomenological Research Methods. London: Sage Publications, 1994.

Oh, Jae E., Jeffrey C. F. Ho, Chris Shaw, and Justin Chan. "Engaging Creative Media Students' Motivation: The Influence of Autonomy, Peer Relationships, and Opportunities in the Industry" World Journal of Education 8, no. 6 (2018). https://doi.org/10.5430/wje. v8n6pl.

Picciano, Antony G., Charles D. Dziuban, and Charles R. Graham. Blended Learning: Research Perspectives. Volume 2. New York: Routledge, 2013.

Ruhl, Joe. "Teaching Methods for Inspiring the Students of the Future: What's love got to do with it?" Youtube TEDx Talks. Published on May 27, 2015. https://www.youtube.com/ watch?v=UCFg9bcW7Bk.

Sanders, Elizabeth B. N., and Pieter J. Stappers. "Co-creation and the New Landscapes of Design." CoDesign 4, no.1 (2008): 5-18.

Wenzel, Thomas J. "AC Educator: Using mistakes as learning opportunities." Analytical Chemistry 74, no.15 (2002): 439-4

\section{Bio}

Gladys Lam worked in advertising for 16 years and served as a creative director of international 4As agencies, winning numerous awards worldwide before joining the Department of Communication Studies, Hong Kong Baptist University in 2006. She taught a variety of advertising design and creativity subjects and supervised honours projects. In addition, Gladys introduced new courses for the school and interdisciplinary general education, presenting the paper in the Global Conference on General Education and University Curriculum Reform at City University of Hong Kong in 2012. She has also published research findings in American Academy of Advertising Global Conference Proceedings. Her current research interests include advertising visual and copy strategies, advertising design and creativity education. 